\title{
Effects of spontaneous heating on estimates of total digestible nutrients for alfalfa-orchardgrass hays packaged in large round bales ${ }^{1}$
}

\author{
W. K. Coblentz ${ }^{* 2}$ and P. C. Hoffman† \\ *USDA-ARS, US Dairy Forage Research Center, Marshfield, WI 54449 \\ †Department of Dairy Science, University of Wisconsin, Madison 53706
}

\begin{abstract}
Large round or large square hay packages are more likely to heat spontaneously during storage than hay packaged in conventional $(45 \mathrm{~kg})$ bales, and the effects of this phenomenon on the associated energy estimates for these hays can be severe. Our objectives for this project were to assess the relationship between estimates of total digestible nutrients (TDN) and spontaneous heating and to describe any important differences in energy estimates that may result specifically from 2 methods of estimating truly digestible fiber (TD-Fiber). Using the summative approach to estimate TDN, TD-Fiber can be estimated from inputs of protein-corrected neutral detergent fiber (NDFn) and acid detergent lignin (TD-FiberLIG) or from NDFn and 48-h neutral detergent fiber digestibility (TDFiberNDFD). Throughout 2006 and 2007, mixed alfalfa (Medicago sativa L.)-orchardgrass (Dactylis glomerata L.) hays from 3 individual harvests were obtained from the same 8.2-ha research site near Stratford, Wisconsin. Both options for estimating TD-Fiber (TD-FiberLIG or TD-FiberNDFD) were then used independently via the summative approach to estimate the total TDN concentrations (TDN-LIG or TDN-NDFD, respectively) within these hays. Estimates of both TDN-LIG and TDN-NDFD then were related to heating degree days $>30^{\circ} \mathrm{C}$ accumulated during storage by various regression techniques. Changes (poststorage - prestorage) in TDN-LIG that occurred during storage ( $\Delta$ TDN-LIG) were best fitted with a nonlinear decay model in which the independent variable was squared $[\mathrm{Y}=(11.7 \times$ $\left.\left.\mathrm{e}^{-0.0000033 \times \mathrm{x} \times \mathrm{x}}\right)-11.6 ; \mathrm{R}^{2}=0.928\right]$. For changes in TDNNDFD ( $\triangle$ TDN-NDFD), a quadratic regression model provided the best fit $\left(\mathrm{Y}=0.0000027 \mathrm{x}^{2}-0.010 \mathrm{x}+\right.$ $\left.0.4 ; \mathrm{R}^{2}=0.861\right)$. Generally, $\Delta \mathrm{TDN}-\mathrm{LIG}$ estimates were 2.0 to 4.0 percentage units lower than $\triangle \mathrm{TDN}-\mathrm{NDFD}$

Received February 2, 2010.

Accepted March 13, 2010.

${ }^{1}$ Mention of trade names or commercial products in this article is solely for the purpose of providing specific information and does not imply either recommendation or endorsement by the USDA.

${ }^{2}$ Corresponding author: wayne.coblentz@ars.usda.gov
\end{abstract}

estimates when heating exceeded 500 HDD. For regressions on maximum internal bale temperature, both $\Delta$ TDN-LIG $\left(\mathrm{Y}=-0.38 \mathrm{x}+16.3 ; \mathrm{R}^{2}=0.954\right)$ and $\Delta$ TDN-NDFD $\left(\mathrm{Y}=-0.25 \mathrm{x}+10.2 ; \mathrm{R}^{2}=0.848\right)$ were best fitted by linear models with heterogeneous $(P<$ 0.001) slopes and intercepts. In both cases, coefficients of determination were high, suggesting that simple measures of spontaneous heating are excellent predictors of energy losses in heated forages. Regardless of method, reductions in TDN were associated primarily with losses of nonfiber carbohydrate, which is known to occur via oxidation of sugars during spontaneous heating. For heated forages, some discrepancy between TDN-LIG and TDN-NDFD existed because the relationship between NDFD and spontaneous heating was shown previously to be very poor, resulting in minimal changes for estimates of TD-FiberNDFD as a consequence of heating. In contrast, TD-FiberLIG declined in close association with heating, largely because TDFiberLIG was sensitive to changes in concentrations of both NDFn and acid detergent lignin. Discrepancies between TDN-LIG and TDN-NDFD were exacerbated further when neutral detergent fiber rather than NDFn was used to estimate TD-FiberNDFD. Estimates of TDN declined by as much as 13.0 percentage units within severely heated hays, and this is a serious consequence of spontaneous heating.

Key words: energy, spontaneous heating, total digestible nutrient

\section{INTRODUCTION}

The harvest of alfalfa (Medicago sativa L.) and other hays can be complicated by poor drying conditions or the threat of unexpected rainfall events, each of which potentially places valuable hay crops at risk. As a result, it is not an uncommon for hay producers to choose between 2 undesirable management options: bale their hay before it is desiccated adequately, or subject their wilting hay crop to rain damage. When hay is packaged before it is desiccated adequately, spontaneous heating is commonly observed during storage and the potential for combustion exists. Recently, we have reported on a series of experiments (Coblentz and Hoffman, 2009a,b; 
Coblentz et al., 2010) describing spontaneous heating within large round bales of alfalfa-orchardgrass (Dactylis glomerata L.) and the subsequent effects of heating on recoveries of DM following storage, as well as on in vitro true digestibility, fiber and protein composition, and ruminal in situ disappearance kinetics of DM, NDF, $\mathrm{CP}$, and neutral detergent insoluble CP (NDICP). In those reports, estimates of 48-h NDF digestibility (NDFD) and effective ruminal degradability of NDF exhibited limited and undetectable responses, respectively, to spontaneous heating (Coblentz and Hoffman, 2009b), thereby raising questions about estimates of total digestible nutrients (TDN) derived from the summative method (Weiss et al., 1992; NRC, 2001) when truly digestible fiber (TD-Fiber) is determined using 48-h NDFD as the digestion coefficient for proteincorrected NDF (NDFn). If TD-Fiber is determined within heated hays by this option (TD-FiberNDFD), it would be sensitive only to fluctuating concentrations of NDFn, primarily because NDFD remained largely static across a fairly wide range of heating (Coblentz and Hoffman, 2009b).

In contrast, TD-Fiber also can be estimated via the acid detergent lignin option (TD-FiberLIG; Weiss et al., 1992; NRC, 2001) that uses inputs of NDFn and acid detergent lignin. Unlike the static nature of NDFD in our heated hays, concentrations of acid detergent lignin increased in curvilinear relationships with heating degree days (HDD) $>30^{\circ} \mathrm{C}$ or maximum internal bale temperature (MAX), exhibiting very high coefficients of determination $\left(\mathrm{R}^{2} \geq 0.885\right.$; Coblentz and Hoffman, $2009 \mathrm{~b})$. The practical consequence of increased concentrations of acid detergent lignin is that TD-FiberLIG is sensitive to concentrations of both NDFn and acid detergent lignin, thereby creating a potential discrepancy between the TD-FiberLIG and TD-FiberNDFD options for estimating TD-Fiber in heated hays. To the best of our knowledge, this potential discrepancy has not been evaluated. Furthermore, changes in the other nutrients that compose summative estimates of TDN, such as truly digestible CP (TD-CP) and truly digestible NFC (TD-NFC), have not been described in detail for heated forages. Our objectives for this project were to assess the relationship between estimates of TDN and spontaneous heating for large round bales of alfalfa-orchardgrass hay and to describe any important differences in energy estimates that may result from the 2 methods of estimating TD-Fiber.

\section{MATERIALS AND METHODS}

\section{Field Procedures}

This project comprised 3 separate hay harvests conducted on the same 8.2-ha field site over a 2-yr period
(2006 and 2007). All details relating to the establishment of forages, soil fertility, harvest management, storage procedures, temperature measurements, and pre- and poststorage sampling procedures have been described previously in detail (Coblentz and Hoffman, 2009a,b; Coblentz et al., 2010). Therefore, these methods are outlined only briefly.

Source of Hays. The forage base at the 8.2-ha field site consisted of a mixture of Phabulous II alfalfa and Extend orchardgrass that was established on April 14, 2004 near Stratford, Wisconsin $\left(44^{\circ} 7^{\prime} \mathrm{N}, 90^{\circ} 1^{\prime} \mathrm{W}\right)$. The overall project consisted of 3 individual harvests, based largely on moisture ranges at baling. The moisture ranges for these harvests were 9.3 to $17.3 \%, 16.8$ to $24.2 \%$, and 26.7 to $46.6 \%$, hereafter designated as low (LM), intermediate (IM), and high (HM) moisture. The LM and HM hay harvests were taken from the second and third cuttings, respectively, during 2006, whereas the IM harvest used forage obtained from the second cutting of 2007. Dry-weight percentages of alfalfa in the LM, IM, and HM harvests were 91,76 , and $68 \%$, respectively, whereas orchardgrass composed 9, 22, and $31 \%$ of each sward, respectively. Because orchardgrass remains strictly vegetative following an initial harvest as hay or silage each spring, only second and third harvests were used for this project, thereby avoiding any potential confounding created by stem elongation within the orchardgrass portion of the sward. Alfalfa was harvested at first flower for the LM harvest and as plants approached full bloom for the IM and HM harvests.

It was necessary to use this multiple-harvest approach to provide adequate quantities of forage for an in-depth evaluation ultimately requiring 96 large round bales, and this objective could not be accomplished with the forage available from a single cutting at the 8.2-ha field site. The treatment structure within each hay harvest was similar; generally, bales were packaged in factorial arrangements of bale diameter $(1.5,1.2$, or $0.9 \mathrm{~m})$ and various concentrations of moisture. In each harvest, forage was mowed and conditioned (Model 8830; J. I. Case Co., Racine, WI), adjacent rows were gathered with a bifold rake, and hay was then baled with a Ford-New Holland round baler (Model BR 740A; CNH America LLC, Racine, WI). All bales were tied with 2 revolutions of net wrap, and each bale was then placed on its rounded side on top of wooden pallets located outdoors over a dense grass sod.

Temperature Measurements. After packaging, each bale was fitted with a thermocouple positioned near its geometric center and bales were monitored daily for internal bale temperature with a hand-held thermocouple thermometer (Omega 450 AKT Type K; Omega Engineering, Stamford, CN). Storage periods lasted 
from July 14 through September 25, 2006 for the LM harvest, July 25 through October 22, 2007 for the IM harvest, and September 1 through December 14, 2006 for the HM harvest. During July, August, September, October, November, and December of 2006, respective mean monthly temperatures were $22.7,19.8,13.4,5.6$, 2.2 , and $-3.6^{\circ} \mathrm{C}$. Similarly, cumulative precipitation for these months totaled 53, 106, 63, 62, 34, and 54 mm, respectively (NOAA, 2006). During July, August, September, and October of 2007, mean monthly temperatures were $20.7,20.2,15.9$, and $11.6^{\circ} \mathrm{C}$, respectively, whereas cumulative precipitation for these months was 85, 245, 96, and $123 \mathrm{~mm}$, respectively (NOAA, 2007). Internal bale temperature data obtained from these hays have been summarized and discussed in a previous report (Coblentz and Hoffman, 2009a).

Bale Sampling Procedures. Each 0.9-, 1.2-, or 1.5$\mathrm{m}$ large round bale was sampled before and after the completion of the outdoor storage period. Immediately after baling, nine 0.46-m deep cores (0.025 m diameter) were taken from the center portion of one side of each bale using a Uni-Forage Sampler (Star Quality Samplers, Edmonton, Alberta, Canada). Sampling holes were filled immediately with spray-foam insulation to eliminate avenues for quick dissipation of heat and moisture from the bale and to prevent air, sunlight, and moisture from having direct access into the bale core. After storage, the surface layer of all bales, regardless of diameter, was sampled (24 probes) to a depth of $0.15 \mathrm{~m}$ over the entire half of the bale surface that was directly opposite from the prestorage sampling sites. These samples were exposed to the weather during storage and were not included in subsequent energy evaluations. Deep-core samples were then taken with a $0.61-\mathrm{m}$ probe for the 1.5 and $1.2-\mathrm{m}$ bale diameters and with a $0.46-\mathrm{m}$ probe for $0.9-\mathrm{m}$ bale diameter through the same 24 sampling holes generated for the surface layer. All samples were dried to constant weight under forced air $\left(50^{\circ} \mathrm{C}\right)$, ground through a Wiley mill (Arthur H. Thomas, Philadelphia, PA) equipped with a 1-mm screen, and then retained for laboratory analyses.

\section{Laboratory Analyses}

To estimate TDN for our heated forages, all pre- and poststorage hay samples were analyzed for fiber composition (NDF, acid detergent lignin), 48-h NDFD, and whole-plant ash, as well as CP, NDICP, and acid detergent insoluble CP (ADICP). Initial evaluation of fiber composition was conducted sequentially using batch procedures outlined by Ankom Technology Corp. (Fairport, NY) for an Ankom200 Fiber Analyzer and was reported previously (Coblentz and Hoffman, 2009b). Neither sodium sulfite nor heat-stable $\alpha$-amylase was included in the NDF solution. Concentrations of whole-plant ash were determined independently for each sample following combustion of 1.0-g samples in a muffle furnace at $500^{\circ} \mathrm{C}$ for $2 \mathrm{~h}$ (Coblentz and Hoffman, 2009a).

Concentrations of $\mathrm{CP}$, NDICP, and ADICP were quantified by a macro-Kjeldahl technique (AOAC, 1998; method 988.05). Prior to analyzing NDF and ADF residues for CP, hay samples were digested independently in neutral and acid detergent, respectively, using the batch procedures outlined by Ankom Technology Corp. The neutral detergent solution did not contain sodium sulfite or heat-stable $\alpha$-amylase; previously, Van Soest et al. (1991) recommended that sodium sulfite be omitted from digestions in neutral detergent that precede quantification of NDICP because sodium sulfite cleaves disulfide bonds and dissolves cross-linked proteins, which reduces protein recovery from NDF residues. In addition, before quantification of ADICP, digestions in acid detergent were conducted nonsequentially, without preliminary digestion in neutral detergent (Van Soest et al., 1991).

Procedures and apparatus for determining NDFD (University of Wisconsin Soil and Forage Analysis Laboratory, Marshfield, WI) consisted of incubating 0.5-g hay samples in 125-mL Erlenmeyer flasks containing rumen fluid, buffer media, and macro- and micromineral solutions (Goering and Van Soest, 1970). Flasks were purged continuously with $\mathrm{CO}_{2}$, maintained in a water bath at $39^{\circ} \mathrm{C}$ for $48 \mathrm{~h}$, and then terminated by digestion in neutral detergent solution that included both heat-stable $\alpha$-amylase and sodium sulfite (Goering and Van Soest, 1970; Mertens, 1992). Prior to ruminal incubation, rumen fluid was harvested from a nonlactating dairy cow fitted with a ruminal cannula and offered a diet containing $59 \%$ alfalfa-grass silage and $40 \%$ corn silage, with the balance consisting of vitamin and mineral supplements.

\section{Calculation of TDN}

The energy concentration of each hay sample was calculated from appropriate laboratory inputs using the equations of Weiss et al. (1992), as adapted by NRC (2001). No processing adjustment factor was applied in this work. Within this context, TDN was defined as

$$
\begin{gathered}
\mathrm{TDN}(\%)=\text { TD-NFC }+ \text { TD-CP }+(\mathrm{TD}-\mathrm{FA} \times 2.25) \\
+ \text { TD-Fiber }- \text { metabolic fecal TDN }
\end{gathered}
$$

where TD-NFC, TD-CP, and TD-Fiber have been defined previously, TD-FA = truly digestible fatty acids, and the metabolic fecal TDN $=7$ percentage units 
(Weiss et al., 1992). The concentration of TD-FA for each forage was estimated as ether extract -1 . This concept is based on the assumption that pigments and waxes, both of which are recovered with FA in ether extract, contain little or no digestible energy and make up approximately $1 \%$ of forage DM (Weiss et al., 1992). For purposes of this evaluation, tabular values (NRC, 2001) were used to approximate concentrations of ether extract. These estimates were based on those provided for (predominantly legume) mixed legume-grass forages subclassified on the basis of concentrations of NDF. The associated multiplier of 2.25 is based on the imperfect premise that lipids and fats contain 2.25 times the energy of carbohydrates (Van Soest, 1982). Concentrations of TD-FiberLIG were calculated as described within NRC (2001) guidelines, based on concentrations of acid detergent lignin and NDFn using the equation TD-FiberLIG $=0.75 \times(\mathrm{NDFn}-$ lignin $) \times[1-($ lignin $/$ $\left.\mathrm{NDFn})^{0.667}\right]$. In this equation, NDFn is expressed as a percentage of DM and calculated as NDF - NDICP. Alternatively, TD-FiberNDFD also was calculated as NDFn $\times($ NDFD/100), where NDFn was expressed as a percentage of DM and NDFD was expressed as a percentage of NDF. Following quantification of TD-FiberLIG or TD-FiberNDFD, TDN was summed over the various component parts, thereby yielding 2 respective estimates of energy for further comparison (TDN-LIG and TDN-NDFD). In practice, these estimates differed only on the basis of methodology for calculating TD-Fiber.

\section{Statistics}

Regression of TDN-NDFD on TDN-LIG. Initially, TDN-LIG and TDN-NDFD were related directly using linear regression analysis, with TDN-LIG identified as the independent variable (PROC REG; SAS Institute, 1990). An additional test statement was included to compare the slope to unity, which would be an essential criterion for ideal agreement between methods. Subsequently, this approach illustrated that there was bias between methods and justified a more in-depth evaluation of the relationship between various truly digestible energy subunits that compose TDN and indices of heating (HDD or MAX).

Regressions of TDN and Truly Digestible Subunits on $H D D$ and $M A X$. Mean concentrations of TD-NFC, TD-CP, TD-FiberLIG, TD-FiberNDFD, TDN-LIG, and TDN-NDFD from 32 combinations of bale moisture and diameter taken from the core of large round bales were pooled from the LM, IM, and HM harvests and then regressed against HDD or MAX. Each data point represented the mean of 3 bales; for each treatment combination of bale moisture and di- ameter, 1 bale was obtained from each of 3 field blocks that were established on the basis of field topography (slope). Although similar across harvests, prestorage concentrations of these total or partial energy components were not identical; therefore, data were normalized before regression analysis as the simple mathematical difference resulting from storage (poststorage - prestorage; i.e., $\Delta$ TD-NFC, $\Delta$ TD-CP, $\Delta$ TD-FiberLIG, $\Delta$ TD-FiberNDFD, $\Delta$ TDN-LIG, and $\Delta$ TDNNDFD), where positive and negative values indicate increased and decreased concentrations, respectively. These variables were then regressed against HDD and MAX using nonlinear regression models (PROC NLIN; SAS Institute, 1990) of the general form $Y=b \times\left(e^{-k x}\right)$ - $a$ if these $\Delta$ response variables became negative with spontaneous heating, or $Y=a-\left(b \times e^{-k x}\right)$ if they became positive. For these model assessments, $k$ was the rate constant, $x$ was the independent variable (HDD or MAX), and $a$ and $b$ were parameters determined directly by the regression model. For nonlinear regression models, the independent variables (HDD or MAX) also were squared in an attempt to improve fit. Linear, quadratic, cubic, and quartic responses to HDD or MAX also were evaluated by PROC REG of SAS (SAS Institute, 1990). Generally, selection of the most appropriate model was based on the greatest coefficient of determination $\left(\mathrm{R}^{2}\right)$; however, polynomial regression models were not selected if the coefficient or slope for the highest ordered term did not differ from zero.

\section{RESULTS AND DISCUSSION}

\section{Regressions of TDN-LIG on TDN-NDFD}

Concentrations of summative energy equation subunits, as well as TDN-LIG and TDN-NDFD, which were derived for hays from the LM, IM, and HM harvests, are summarized in Table 1. For estimated hay energies, the bias between estimates of TDN determined by TDN-NDFD or TDN-LIG is illustrated by simple linear regression (Figure 1). When TDN-LIG was designated as the independent variable, the resulting slope $(0.73)$ differed from unity $(P<0.001)$ and the intercept $(15.4)$ differed $(P<0.001)$ from zero; however, the coefficient of determination was very high $\left(\mathrm{R}^{2}=0.953\right)$, indicating the 2 methods were associated closely. Generally, these findings suggest that the bias between the 2 methods of calculating TDN was greatest for low-TDN hays, which had previously incurred the most severe spontaneous heating. Under these circumstances, estimates of TDN-NDFD were consistently greater than those derived from TDN-LIG; however, this bias was largely undetectable when spontaneous heating was minimal and TDN exceeded about $55 \%$. 
Table 1. Concentrations of truly digestible NFC (TD-NFC), truly digestible CP (TD-CP), truly digestible fiber (TD-Fiber) determined by 48-h NDF digestibility (TD-FiberNDFD), TD-Fiber determined by lignin approximation (TD-FiberLIG), and total digestible nutrients (TDN) determined by the 2 methods of calculating TD-Fiber (TDN-LIG and TDN-NDFD) summarized from round bales of alfalfa-orchardgrass hay made from 3 harvests during 2006 and 2007 at Stratford, Wisconsin

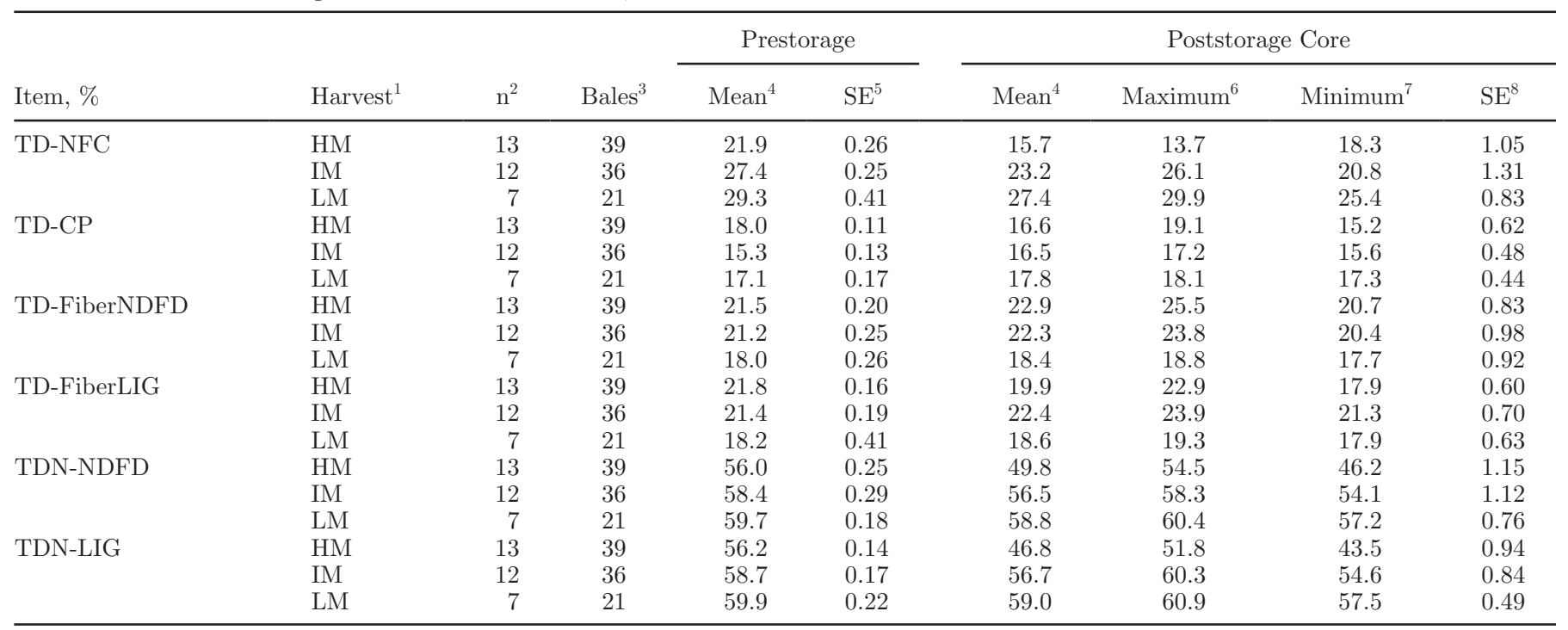

${ }^{1}$ Harvest: $\mathrm{HM}=$ high moisture $(26.7$ to $46.6 \%)$; IM = intermediate moisture (16.8 to $\left.24.2 \%\right)$; LM = low moisture $(9.3$ to $17.3 \%)$.

${ }^{2}$ Number of interactive treatments during each harvest. Harvest HM contained 1 baling treatment made at $26.7 \%$ moisture at the 0.9 -m bale diameter only, whereas harvest LM contained 1 dry control made at $9.3 \%$ moisture at the $1.2-\mathrm{m}$ bale diameter only. These additional treatments were made at only 1 diameter because insufficient forage was available to complete the entire factorial arrangement of treatments (bale diameters) at these moisture concentrations. Each interactive treatment represents the mean of 3 bales.

${ }^{3}$ Total numbers of bales made per harvest.

${ }^{4}$ Overall mean of all interactive bale moisture $\times$ bale diameter treatments.

${ }^{5}$ Standard error of the overall mean of all interactive bale moisture $\times$ bale diameter treatments.

${ }^{6}$ Maximum values across all interactive treatments.

${ }^{7}$ Minimum values across all interactive treatments.

${ }^{8}$ Standard error of the interactive (bale moisture $\times$ bale diameter) mean.

\section{Summative Equation Subunit Evaluation}

$\boldsymbol{T D}$-NFC. Regressions of $\triangle \mathrm{TD}-\mathrm{NFC}$ on both HDD (Figure 2a) and MAX (Figure 2b) were best fitted to nonlinear decay models in which the independent variable was squared. In both cases, $\triangle \mathrm{TD}-\mathrm{NFC}$ declined rapidly with low or modest heating before becoming asymptotic at approximately $660 \mathrm{HDD}$ or $60^{\circ} \mathrm{C}$ MAX when $\triangle \mathrm{TD}-\mathrm{NFC}=-6.2$ or -6.4 percentage units of TDN, respectively. Both measures of spontaneous heating (HDD and MAX) explained approximately $70 \%$ of the variation within $\triangle \mathrm{TD}-\mathrm{NFC}\left(\mathrm{R}^{2}=0.686\right.$ and 0.712 , respectively). In the summative model (NRC, 2001), NFC is estimated as residual DM, which is not included within pools of NDFn, CP, ether extract, or ash; therefore, NFC represents primarily plant sugars that are known to be oxidized when hays heat spontaneously. In practice, the responses exhibited by $\triangle \mathrm{TD}-\mathrm{NFC}$ in regressions on HDD and MAX are essentially mirror-opposite responses from those exhibited by concentrations of NDF for these same hays (Coblentz and Hoffman, 2009b). Concentrations of NDF within heated hays increase primarily by losses of nonfiber constituents, whereas true fiber components remain largely inert (Rotz and Muck, 1994). In a previous study (Coblentz et al., 1997), alfalfa hay packaged at 29.7 and $20.2 \%$ moisture within small rectangular bales exhibited poststorage concentrations of total nonstructural carbohydrates of 2.1 and $4.2 \%$ of DM, which were only 35 and $58 \%$, respectively, of the concentrations reported for corresponding prestorage controls (Coblentz et al., 1997). These data suggested that oxidation (losses) of nonstructural carbohydrates can be substantial as a consequence of spontaneous heating, or storage, or both, even when heating is relatively limited in scope. More importantly, the oxidative losses observed in the current study, as well as past studies, have serious consequences with respect to the final energy estimates of the hay because the true digestibility coefficient for NFC is 0.98 (Weiss et al., 1992; NRC, 2001), which is based on Lucas-test analysis of neutral detergent solubles from cattle and sheep fed at maintenance (Van 


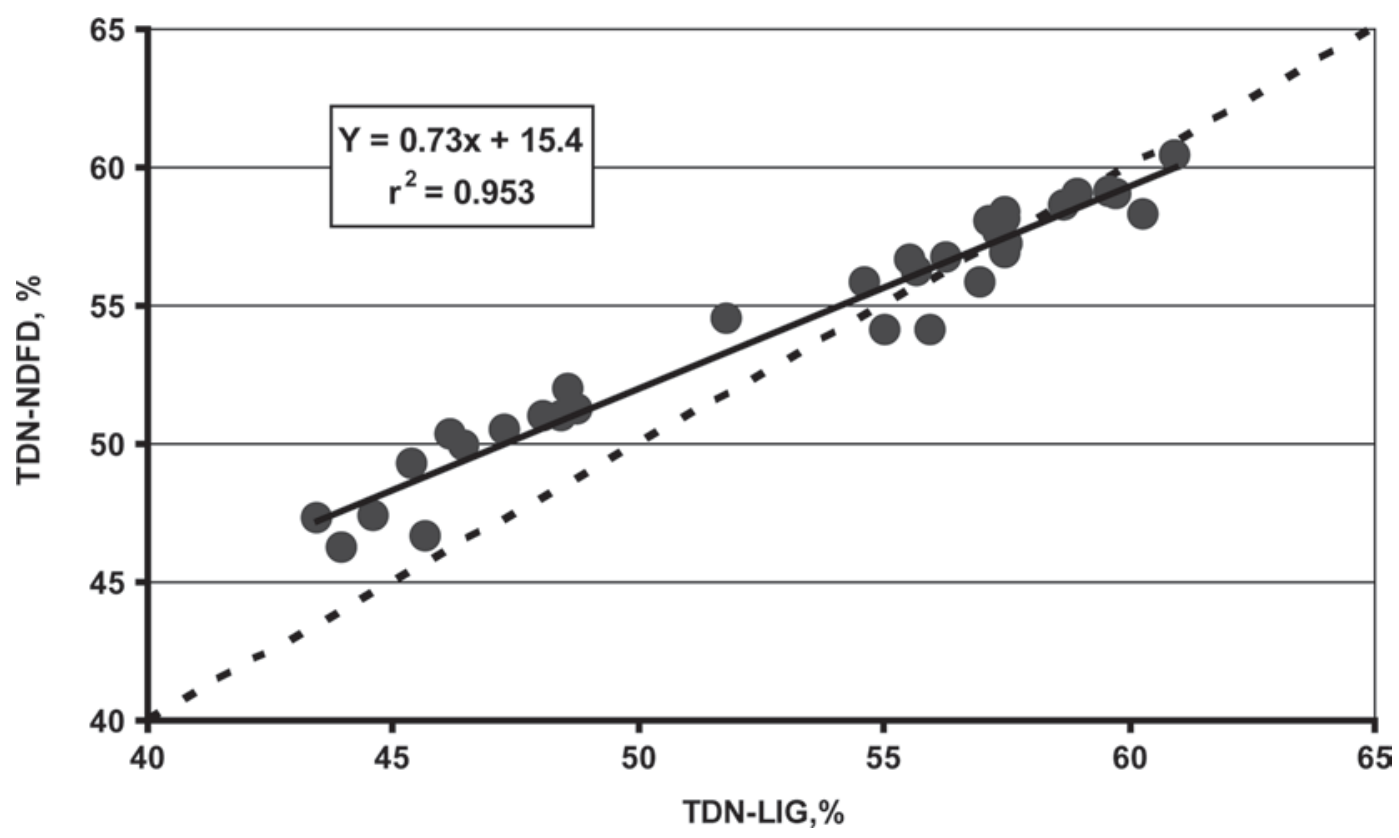

Figure 1. Linear regression relating estimates of total digestible nutrients (TDN) determined by the 48-h NDF digestibility (TDN-NDFD) to those determined with the lignin approximation for truly digestible fiber (TDN-LIG) for heat-damaged alfalfa-orchardgrass hays. Diagonal hashed line represents ideal agreement between methods with slope $=1$ and intercept $=0$.

Soest, 1982). Therefore, NFC approaches ideality as a feed fraction, implying near complete bioavailability, and any loss of NFC as a consequence of spontaneous heating results in a near identical and direct loss of TDN units from the final energy estimate for the hay.

$\boldsymbol{T D} \boldsymbol{C} \boldsymbol{C P}$. Regressions of $\Delta \mathrm{TD}-\mathrm{CP}$ on HDD (Figure $3 \mathrm{a}$ ) and MAX (Figure $3 \mathrm{~b}$ ) indicate that $\triangle \mathrm{TD}-\mathrm{CP}$ was positive with minimal to modest spontaneous heating that ranged generally up to $500 \mathrm{HDD}$ or $60^{\circ} \mathrm{C}$ MAX, but became negative as spontaneous heating became more extreme. For HDD, data were best fitted $\left(\mathrm{R}^{2}=\right.$ 0.812 ) to the nonlinear decay model with the independent variable squared. For this regression, the curve became asymptotic at approximately 1,450 HDD when $\Delta \mathrm{TD}-\mathrm{CP}=-2.6$ percentage units of TDN. Although $\triangle \mathrm{TD}-\mathrm{CP}$ generally exhibited a similar response pattern when regressed on MAX, a cubic polynomial model provided the best fit $\left(\mathrm{R}^{2}=0.864\right)$.

Generally, the concentration of CP increases slightly in heated hays, particularly in the short term $(<60 \mathrm{~d}$; Rotz and Muck, 1994). Mostly, this occurs because forage carbohydrates, particularly sugars, are preferentially oxidized during storage, thereby concentrating $\mathrm{CP}$ indirectly. In our study, averaged over all treatments and harvests, the average change in $\mathrm{CP}$ concentration was $1.0 \pm 0.67$ percentage units during storage (Coblentz et al., 2010), which supports the premise established by Rotz and Muck (1994). A second factor affecting estimates of TD-CP derived from summative energy equa- tions is ADICP (Weiss et al., 1992; NRC, 2001). When expressed as a proportion of CP, ADICP is highly correlated with digestibility of forage $\mathrm{CP}$ and this relationship is used to estimate TD-CP (Thomas et al., 1982; Weiss et al., 1983). In the summative model, TD-CP in forages is calculated as $\mathrm{CP} \times \mathrm{e}^{[-1.2 \times(\mathrm{ADICP} / \mathrm{CP})]}$, where ADICP is expressed as a percentage of DM (Weiss et al., 1992; NRC, 2001). In practice, the expression $\mathrm{e}^{[-1.2 \times(\mathrm{ADICP} / \mathrm{CP})]}$ approaches 1.0 when ADICP is in its native form within unheated alfalfa hays and composes a relatively small proportion of the total $\mathrm{CP}$ pool. Over several studies (Hoffman et al., 1993; Coblentz et al., 1996; Coblentz et al., 1998; Ogden et al., 2006), concentrations of ADICP have ranged between 0.7 and $1.6 \%$ of DM for oven-dried alfalfa forages and unheated hays. Within these forages, the corresponding coefficient generated by $\mathrm{e}^{[-1.2 \times(\mathrm{ADICP} / \mathrm{CP})]}$ ranged narrowly from 0.90 to 0.96 , thereby indicating that TD-CP is driven primarily by the concentration of $\mathrm{CP}$ within any specific unheated alfalfa forage. In our present study with heated hays, actual concentrations of ADICP ranged broadly from 1.1 to $4.5 \%$ of DM (Coblentz et al., 2010), yielding values for the $\mathrm{e}^{[-1.2 \times(\mathrm{ADICP} / \mathrm{CP})]}$ term that varied from 0.94 for unheated hays to a minimum of 0.76 for those hays incurring the most extreme spontaneous heating. As a result, estimates of $\triangle \mathrm{TD}-\mathrm{CP}$ were positive with low or limited heating, largely in response to slight increases in concentrations of $\mathrm{CP}$ coupled with relatively stable estimates of $\mathrm{e}^{[-1.2 \times(\mathrm{ADICP} / \mathrm{CP})]}$. At more 

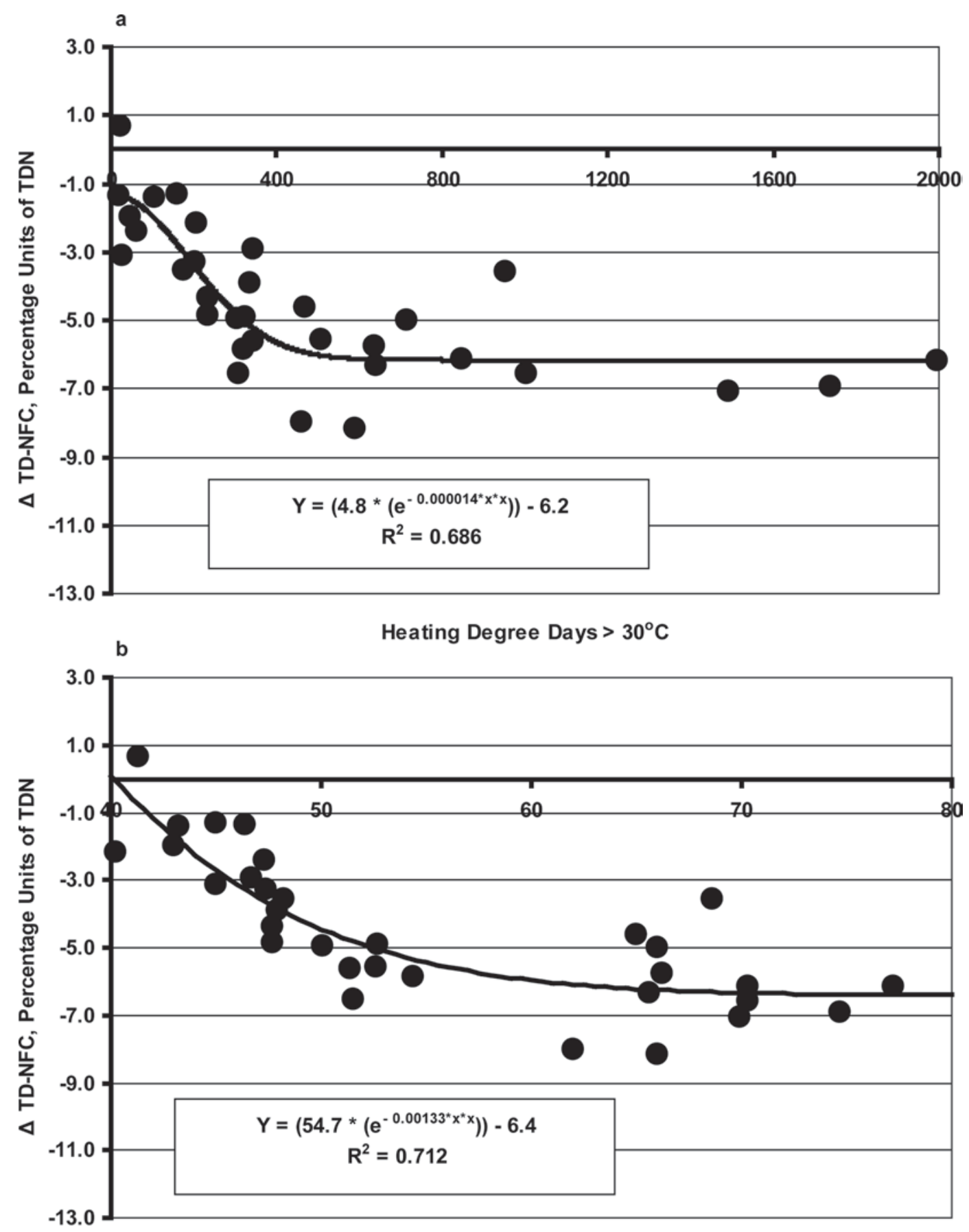

Maximum Temperature, ${ }^{\circ} \mathrm{C}$

Figure 2. Nonlinear regressions of the change in truly digestible NFC (poststorage - prestorage; $\Delta$ TD-NFC) on a) heating degree days $>30^{\circ} \mathrm{C}$ and b) maximum internal bale temperature. The mean prestorage concentration of TD-NFC (weighted on the basis of the number of treatments from the low, intermediate, and high moisture harvests) was $25.6 \%$, which corresponds generally to $\Delta \mathrm{TD}-\mathrm{NFC}=0$ on the $\mathrm{y}$-axis. $\mathrm{TDN}=$ total digestible nutrients.

extreme levels of heating, the coefficient generated by $\mathrm{e}^{[-1.2 \times(\mathrm{ADICP} / \mathrm{CP})]}$ decreased by as much as $19 \%$, thereby resulting in negative estimates of $\triangle \mathrm{TD}-\mathrm{CP}$.

$\boldsymbol{T D}$-Fiber. Regressions of $\Delta \mathrm{TD}$-FiberLIG or $\Delta \mathrm{TD}$ FiberNDFD on HDD (Figure 4a) depict somewhat contrasting responses to spontaneous heating. The relationship between $\triangle \mathrm{TD}$-FiberLIG and HDD was best fitted to the nonlinear decay model with the independent variable squared, which explained approximately two-thirds of the variation in the data $\left(\mathrm{R}^{2}=0.676\right)$. 


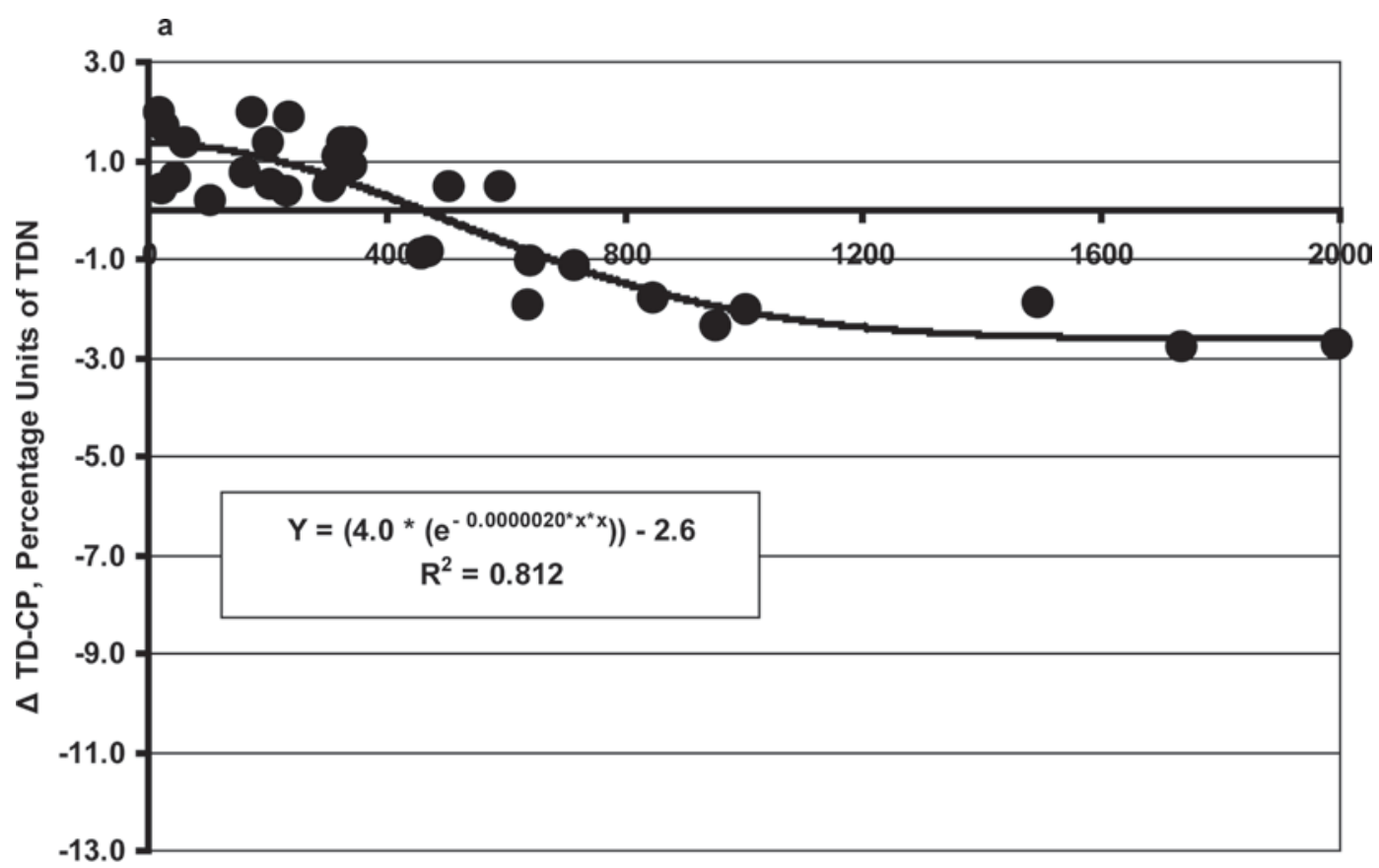

b

Heating Degree Days $>30^{\circ} \mathrm{C}$

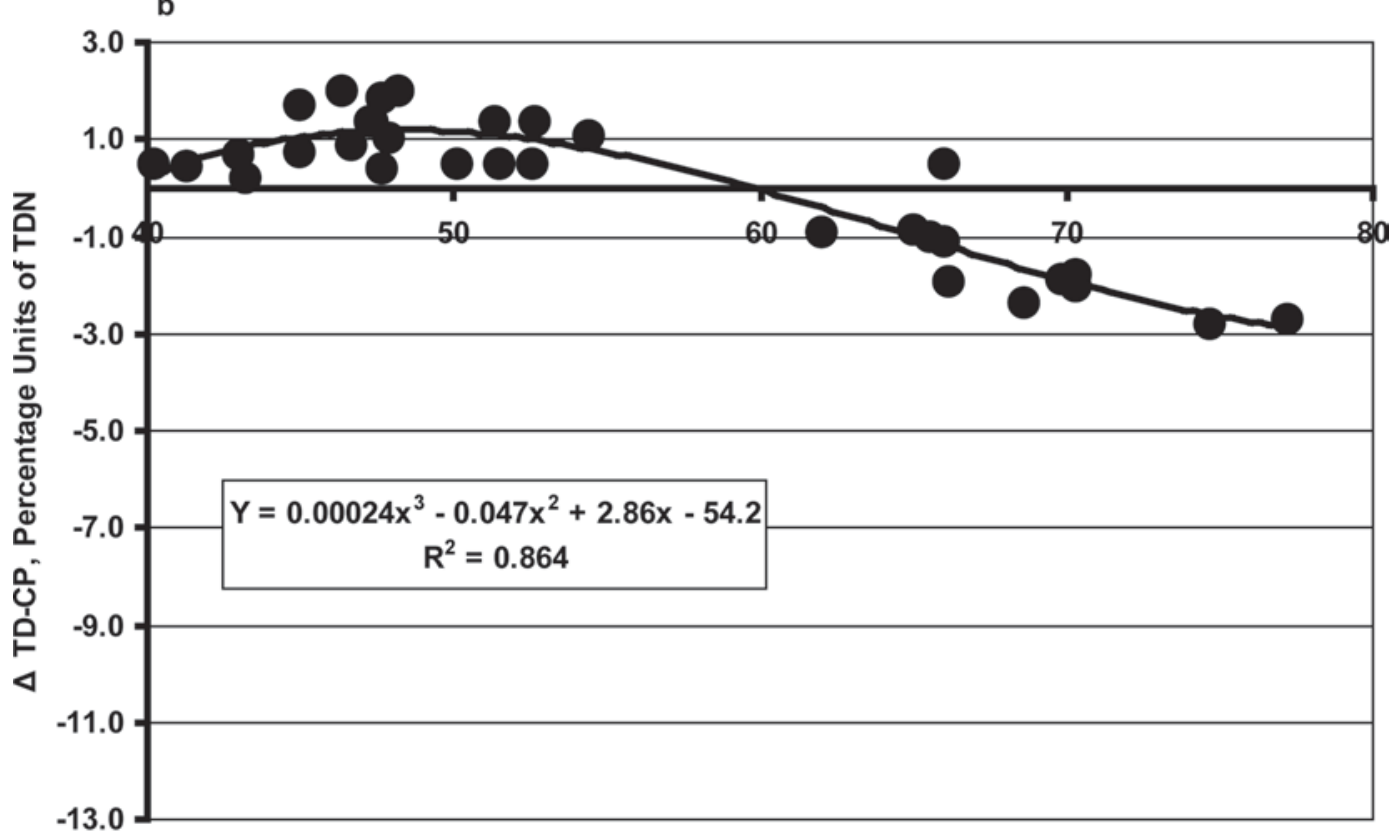

Maximum Temperature, ${ }^{\circ} \mathrm{C}$

Figure 3. Nonlinear regressions of the changes in truly digestible CP (poststorage - prestorage; $\Delta \mathrm{TD}-\mathrm{CP}$ ) on a) heating degree days $>30^{\circ} \mathrm{C}$ and b) maximum internal bale temperature. The mean prestorage concentration of TD-CP (weighted on the basis of the number of treatments from the low, intermediate, and high moisture harvests) was $16.8 \%$, which corresponds generally to $\Delta \mathrm{TD}$-CP $=0$ on the $\mathrm{y}$-axis. TDN $=$ total digestible nutrients.

In this relationship, $\Delta$ TD-FiberLIG remained positive, indicating that TD-FiberLIG had increased relative to prestorage estimates until approximately 400 HDD were accumulated. After that point, $\Delta$ TD-FiberLIG was negative over the remainder of the heating continuum and became asymptotic at approximately 1,500 HDD when $\triangle$ TD-FiberLIG $=-3.2$ percentage units of TDN. In contrast, the regression of $\triangle \mathrm{TD}$-FiberNDFD 
on HDD (Figure $4 \mathrm{~b})$ was fitted poorly $\left(\mathrm{R}^{2}=0.203\right)$ to a quadratic model in which $\triangle$ TD-FiberNDFD remained positive up to approximately 1,800 HDD. However, $\triangle \mathrm{TD}-F i b e r N D F D$ did not deviate from 0 (no change) for any baling treatment by more than 3.0 percentage units, thereby indicating that the effects of $\Delta \mathrm{TD}$ FiberNDFD on subsequent estimation of TDN may be relatively small.

These contrasting responses are likely nuances of methodology. Both methods of estimating TD-Fiber (TD-FiberLIG or TD-FiberNDFD) are sensitive to changes (increases) in concentrations of NDFn induced by spontaneous heating. For hays in this study, concentrations of NDF, uncorrected for NDICP, increased by 8.6 percentage units as a result of spontaneous heating (Coblentz and Hoffman, 2009b). Over the LM, IM, and HM hay harvests, poststorage concentrations of acid detergent lignin approximately doubled over our continuum of heating, ranging from 5.00 to $9.99 \%$ (Coblentz and Hoffman, 2009b). Because estimation of TD-FiberLIG requires this input (NRC, 2001), our estimates of TD-FiberLIG also were responsive to changes in acid detergent lignin. In contrast, TD-FiberNDFD was calculated as the simple product of NDFn and 48-h NDFD. Previously, we summarized concentrations of NDFD for these hays and found only a weak linear relationship $\left(\mathrm{Y}=-0.0023 \mathrm{x}+0.8 ; \mathrm{r}^{2}=0.310\right)$ between NDFD and HDD (Coblentz and Hoffman, 2009b). Furthermore, this relationship was influenced heavily by reduced concentrations of NDFD within only 4 of the 32 total baling treatments that incurred the most extreme spontaneous heating. When extreme heating was eliminated from the data set, the relationship between NDFD and HDD did not approach significance $(P=$ $0.950)$. As a result of these factors, $\triangle$ TD-FiberNDFD remained positive throughout virtually the entire continuum of HDD, responding only to increased concentrations of NDFn because there was no appreciable change in NDFD for all baling treatments except those incurring severe heating.

Regressions of $\Delta$ TD-FiberLIG and $\Delta$ TD-FiberNDFD on MAX (Figure 4b) both were best fitted to quadratic regression models. However, as observed for regressions on HDD, $\triangle$ TD-FiberNDFD remained positive over almost the entire heating continuum for MAX, whereas $\triangle \mathrm{TD}$-FiberLIG became negative at approximately $60^{\circ} \mathrm{C}$ and continued to decline thereafter. Within regressions on HDD and MAX, coefficients of determination were substantially greater for $\Delta$ TD-FiberLIG $\left(\mathrm{R}^{2}=0.676\right.$ and 0.759 , respectively) than for $\triangle \mathrm{TD}$-FiberNDFD $\left(\mathrm{R}^{2}=0.203\right.$ and 0.377 , respectively). Differences in relationship fit associated with the 2 dependent variables probably can be explained by a combination of factors related to the 48-h NDFD measurement itself:
1) NDFD is a relatively imprecise and variable measurement typically exhibiting relatively high standard errors; 2) NDFD is 1 of only 2 factors multiplied directly to determine TD-FiberNDFD; and 3) there was little evidence to suggest that NDFD was affected by spontaneous heating, particularly within bales incurring low to modest levels of HDD or MAX (Coblentz and Hoffman, 2009b).

\section{TDN}

Estimates of $\triangle$ TDN-LIG and $\triangle T$ TDN-NDFD were related to HDD (Figure 5a) with a nonlinear decay model in which HDD was squared and with a quadratic regression model, respectively. Both relationships were characterized by high coefficients of determination $\left(\mathrm{R}^{2}\right.$ $\geq 0.861$ ), indicating that the poor relationship between $\triangle$ TD-FiberNDFD subunit and HDD that was discussed previously had only limited effects on the overall estimation of TDN. For $\triangle$ TDN-LIG, the nonlinear regression curve became asymptotic at approximately 1,300 HDD when $\triangle$ TDN-LIG $=-11.6$ percentage units of TDN. These responses were about 2.0 to 4.0 percentage units more negative than the corresponding regression for $\triangle T D N-N D F D$ whenever heating exceeded about 500 HDD. For regressions on MAX (Figure 5b), both $\triangle$ TDN-LIG and $\triangle$ TDN-NDFD were best fitted by linear models; in both cases, coefficients of determination were high $\left(R^{2}=0.954\right.$ and 0.848 , respectively), again suggesting that simple measures of spontaneous heating are excellent predictors of energy depressions for heated forages. Although both regressions on MAX were linear, the general relationship between $\triangle$ TDN-LIG and $\triangle$ TDN-NDFD was consistent with that observed for relationships with HDD. The slope associated with $\triangle$ TDN-LIG was more negative than that observed for $\triangle$ TDN-NDFD $(-0.38$ vs. $-0.25 ; P<0.001)$, and respective intercepts for these regressions differed (16.3 vs. $10.2 ; P<0.001)$. As a result, $\Delta$ TDN-LIG was consistently more negative than $\triangle \mathrm{TDN}-\mathrm{NDFD}$ when MAX exceeded $45^{\circ} \mathrm{C}$, reaching a maximum differential of -3.9 percentage units at the greatest $\operatorname{MAX}\left(77.2^{\circ} \mathrm{C}\right)$.

\section{Importance of Using NDFn}

Although our calculations of TD-FiberNDFD (and subsequently TDN-NDFD) have been based strictly on NDFn, NRC (2001) guidelines and associated programming codes specify only that TD-FiberNDFD can be estimated using NDFD as a digestibility coefficient for NDF. Intuitively, use of NDFn is logical for calculating TD-FiberNDFD because contributions made by NDICP to TDN already have been considered during estimation of the TD-CP energy subunit. In practice, 

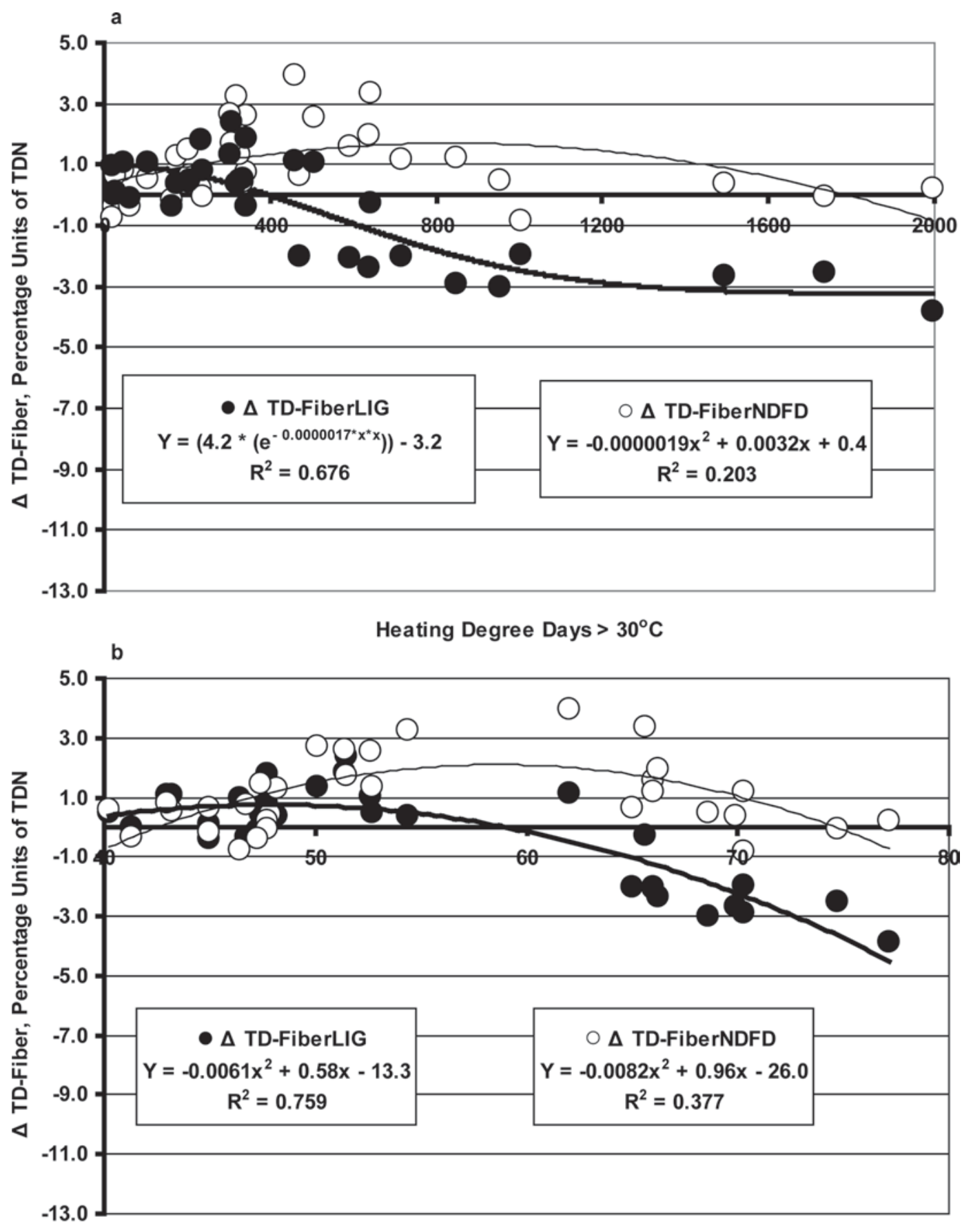

Maximum Temperature, ${ }^{\circ} \mathrm{C}$

Figure 4. Nonlinear regressions of the changes (poststorage - prestorage) in truly digestible fiber (TD Fiber) as estimated by lignin equation ( $\Delta$ TD-FiberLIG; $\bullet$, thick line) and by 48 -h NDF digestibility ( $\Delta$ TD-FiberNDFD; $\mathrm{O}$, thin line) on a) heating degree days $>30^{\circ} \mathrm{C}$ and $\mathrm{b}$ ) maximum internal bale temperature. The mean prestorage concentrations of TD-FiberLIG and TD-FiberNDFD weighted on the basis of the number of treatments from the low, intermediate, and high moisture harvests were 20.9 and $20.6 \%$, respectively, which correspond generally to $\Delta$ TD-FiberLIG or $\Delta$ TD-FiberNDFD $=0$ on the y-axis. TDN $=$ total digestible nutrients.

the concentration of NDICP is relatively low in most unheated dairy-quality forages and it is evaluated inconsistently throughout commercial forage evaluation packages. Therefore, actual values for NDICP are commonly unavailable or approximated, or the protein correction of NDF is ignored entirely when calculating TD-FiberNDFD and, subsequently, TDN-NDFD. Across the LM, IM, and HM harvests, prestorage means 


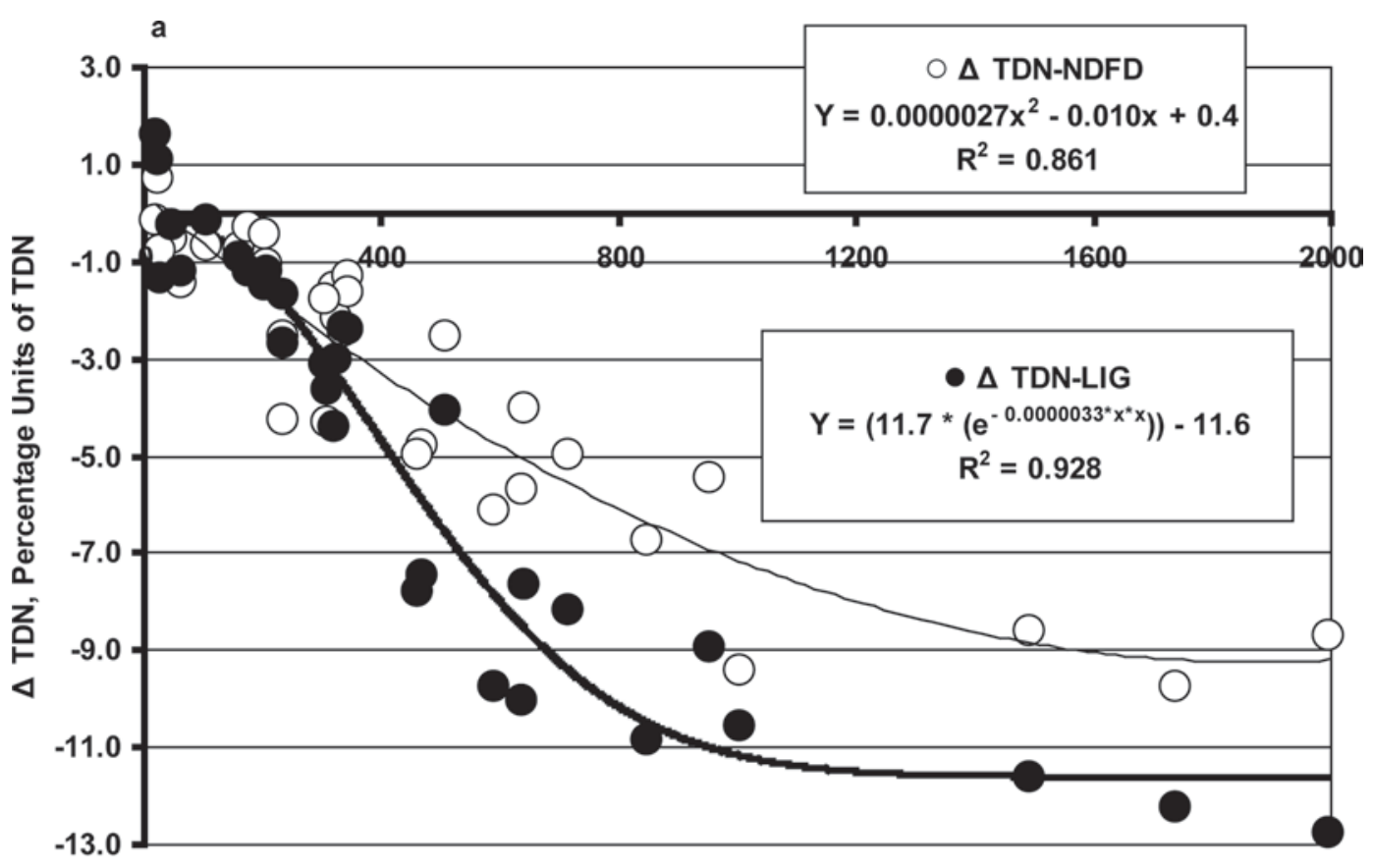

b

Heating Degree Days $>30^{\circ} \mathrm{C}$

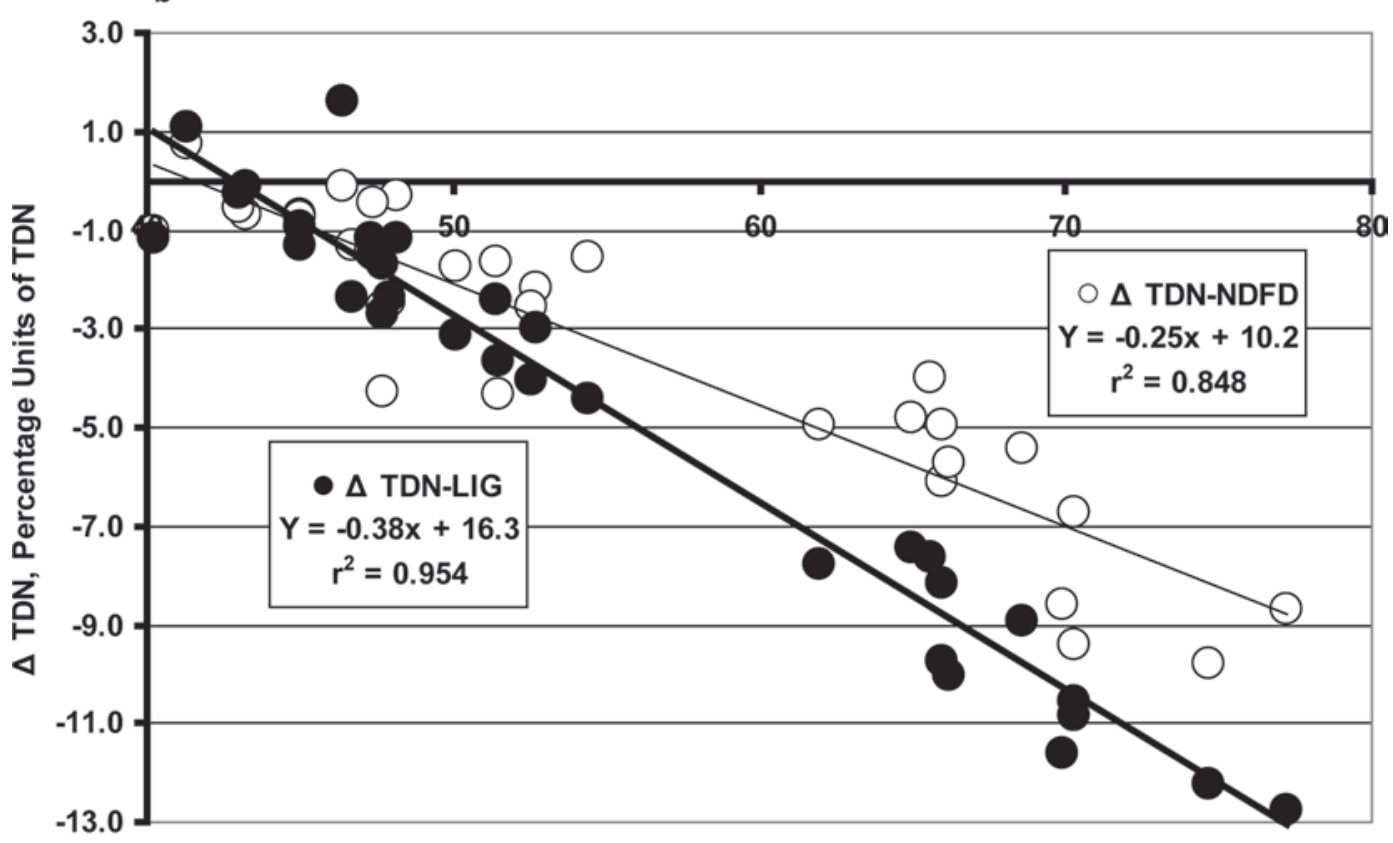

Maximum Temperature, ${ }^{\circ} \mathrm{C}$

Figure 5. Nonlinear regressions of the changes (poststorage - prestorage) in total digestible nutrients (TDN) with truly digestible fiber estimated by lignin equation ( $\triangle \mathrm{TDN}-\mathrm{TIG} ; \bullet$, thick line) and by 48 -h NDF digestibility ( $\Delta$ TDN-NDFD; $\bigcirc$, thin line) on a) heating degree days $>30^{\circ} \mathrm{C}$ and b) maximum internal bale temperature. The mean prestorage concentrations of TDN-LIG and TDN-NDFD weighted on the basis of the number of treatments from the low, intermediate, and high moisture harvests were 57.9 and $57.7 \%$, respectively, which correspond generally to $\triangle$ TDN-LIG and $\triangle$ TDN-NDFD $=0$ on the $y$-axis.

for NDICP ranged from 3.5 to $3.9 \%$ of $\mathrm{DM}$ (18.4 to $21.9 \%$ of CP; Coblentz et al., 2010); therefore, protein correction of NDF likely has only limited relevance for estimates of TD-FiberNDFD from unheated forages.
However, within severely heated hays, concentrations of NDICP ranged as high as $9.3 \%$ of DM $(47.6 \%$ of CP; Coblentz et al., 2010), thereby greatly increasing the potential for discrepancy between methods. This 


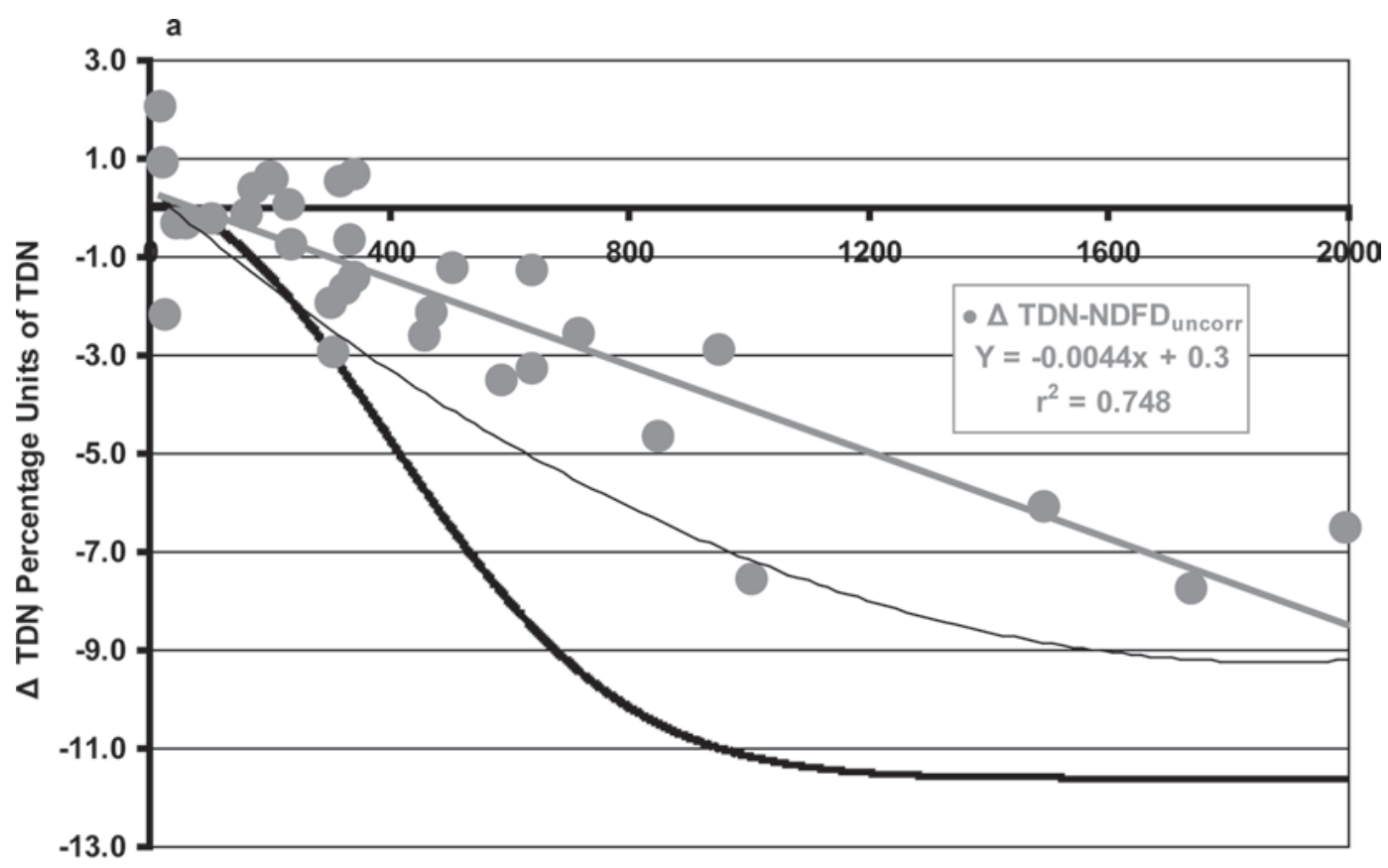

b

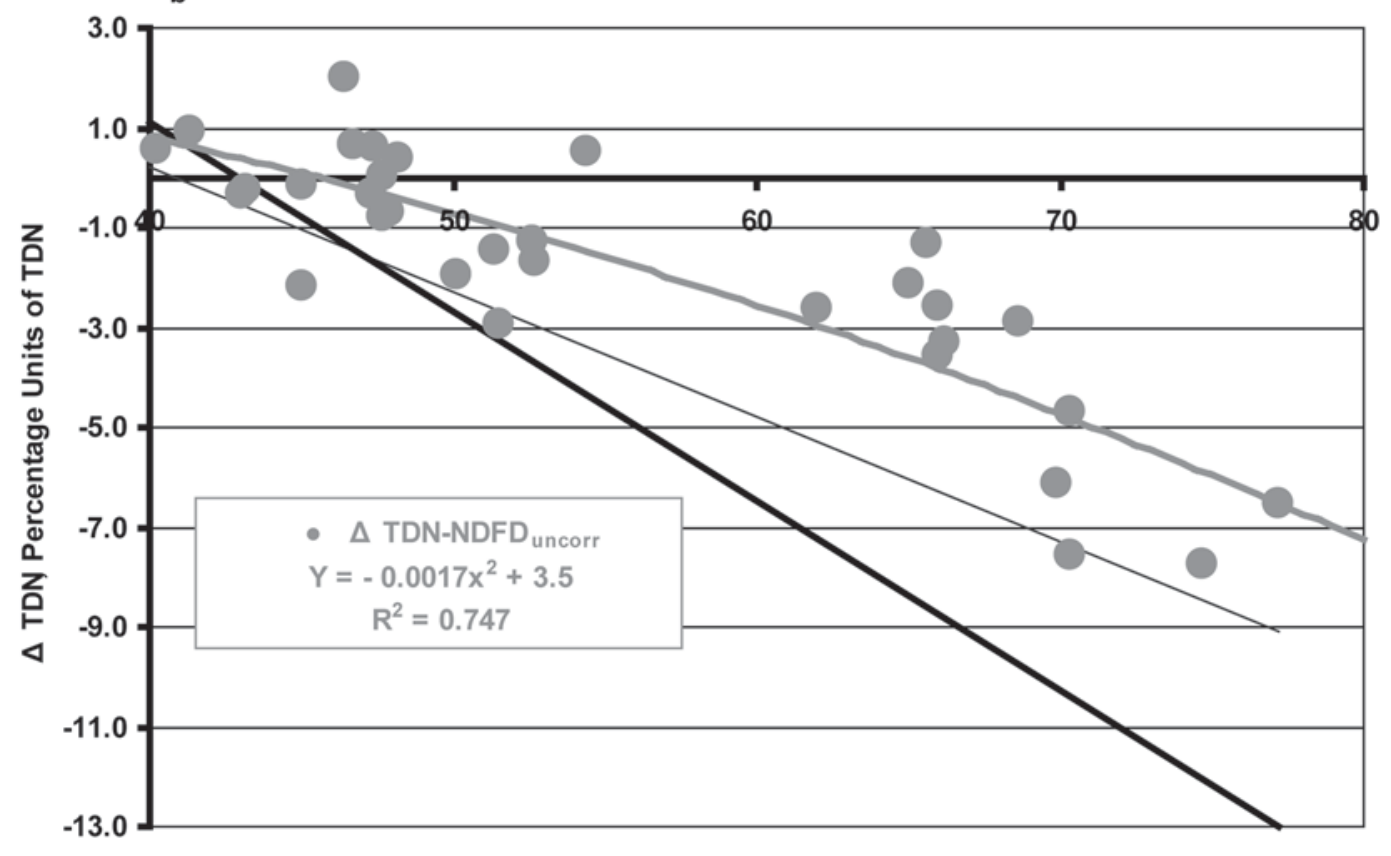

Maximum Temperature, ${ }^{\circ} \mathrm{C}$

Figure 6. Regressions of the changes (poststorage - prestorage) in concentrations of total digestible nutrients (TDN) on spontaneous heating when truly digestible fiber was estimated from NDF (rather than protein-corrected NDF) with 48-h NDF digestibility as the corresponding digestibility coefficient $\left(\triangle \mathrm{TDN}-\mathrm{NDFD}_{\text {uncorr }}\right.$; gray dot, gray line). Responses are regressed on a) heating degree days $>30^{\circ} \mathrm{C}$ and $\left.\mathrm{b}\right)$ maximum internal bale temperature. The mean prestorage concentration of TDN-NDFD uncorr, weighted on the basis of the number of treatments from the low, intermediate, and high moisture harvests, was $59.5 \%$ and corresponds generally to $\Delta$ TDN-NDFD ${ }_{\text {ncorr }}=0$ on the y-axis. Regression lines for change in TDN with truly digestible fiber estimated by lignin equation ( $\Delta$ TDN-LIG; thick black line) and by 48 -h NDF digestibility ( $\Delta$ TDNNDFD; thin black line) are described in Figure 5 and are provided here for reference. 
concept is illustrated in Figure 6, where NDF, rather than NDFn, was used to calculate TDN-NDFD (TDNNDFD $_{\text {uncorr }}$ ). Changes (poststorage - prestorage) in TDN-NDFD uncorr $_{\text {during storage }(\Delta \text { TDN-NDFD }}$ uncorr $)$ were regressed on HDD yielding a simple linear relationship that explained approximately three-fourths of the variation within the data $(\mathrm{Y}=-0.0044 \mathrm{x}+0.3$; $\mathrm{R}^{2}=0.748$; Figure $\left.6 \mathrm{a}\right)$. For the regression on MAX, a quadratic response, without the linear term, was the most appropriate response model $\left(\mathrm{Y}=-0.0017 \mathrm{x}^{2}+\right.$ $3.5 ; \mathrm{R}^{2}=0.747$; Figure $\left.6 \mathrm{~b}\right)$. Generally, these regressions illustrate that deviations by $\triangle T D N-N D F D_{\text {uncorr }}$ from $\triangle$ TDN-LIG were approximately twice those observed for $\triangle$ TDN-NDFD for any hay incurring at least modest spontaneous heating. As a result, the regression curve established for $\triangle \mathrm{TDN}-\mathrm{NDFD}_{\text {uncorr }}$ ranged up to 7 percentage units of TDN higher than that observed for $\triangle$ TDN-LIG. As such, any use of the NDFD option for determining TD-Fiber and, subsequently, TDN, should use NDFn if there is any corroborating evidence suggesting that hays heated during storage.

\section{IMPLICATIONS}

Estimates of TDN from hays are reduced as a consequence of spontaneous heating during storage. Most of the reduced concentrations of energy within these heated forages are associated with losses of TD-NFC, which occurs primarily via oxidation of sugars. For heated forages, some discrepancy exists between estimates of TD-FiberLIG compared with those estimated by the alternative TD-FiberNDFD approach. The poor association between NDFD and spontaneous heating caused only minimal changes in TD-FiberNDFD over an extensive range of heating. In contrast, TD-FiberLIG declined in close association with heating, largely because this approximation is sensitive to changes in both NDFn and acid detergent lignin. Discrepancies between TDN-LIG and TDN-NDFD were exacerbated further when NDF rather than NDFn was used to estimate TD-FiberNDFD. As such, any use of the NDFD option for determining TD-Fiber, and subsequently TDN, should use NDFn if there is any other evidence suggesting that hays were heated during storage. In severely heated hays from large round bales, estimates of TDN declined by as much as 13.0 percentage units during storage, and this is a serious consequence of spontaneous heating.

\section{REFERENCES}

AOAC. 1998. Official Methods of Analysis. 16th ed. 4th rev. Association of Official Analytical Chemists, Gaithersburg, MD.
Coblentz, W. K., J. O. Fritz, K. K. Bolsen, and R. C. Cochran. 1996. Quality changes in alfalfa hay during storage in bales. J. Dairy Sci. 79:873-885.

Coblentz, W. K., J. O. Fritz, K. K. Bolsen, R. C. Cochran, and L. Fu. 1997. Relating sugar fluxes over time to quality changes in alfalfa hay. Agron. J. 88:800-806.

Coblentz, W. K., J. O. Fritz, W. H. Fick, R. C. Cochran, and J. E. Shirley. 1998. In situ dry matter, nitrogen, and fiber degradation of alfalfa, red clover, and eastern gamagrass at four maturities. J. Dairy Sci. 81:150-161.

Coblentz, W. K., and P. C. Hoffman. 2009a. Effects of bale moisture and bale diameter on spontaneous heating, dry matter recovery, in vitro true digestibility, and in situ disappearance kinetics of alfalfaorchardgrass hays. J. Dairy Sci. 92:2853-2874.

Coblentz, W. K., and P. C. Hoffman. 2009b. Effects of spontaneous heating on fiber composition, fiber digestibility, and in situ disappearance kinetics of NDF for alfalfa-orchardgrass hays. J. Dairy Sci. 92:2875-2895.

Coblentz, W. K., P. C. Hoffman, and N. P. Martin. 2010. Effects of spontaneous heating on forage protein fractions and in situ disappearance kinetics of crude protein for alfalfa-orchardgrass hays packaged in large round bales. J. Dairy Sci. 93:1148-1169.

Goering, H. K., and P. J. Van Soest. 1970. Forage Fiber Analyses (Apparatus, Reagents, Procedures, and Some Applications). Agric. Handbook No. 379. USDA-ARS, Washington, DC.

Hoffman, P. C., S. J. Sievert, R. D. Shaver, D. A. Welch, and D. K. Combs. 1993. In situ dry matter, protein, and fiber degradation of perennial forages. J. Dairy Sci. 76:2632-2643.

Mertens, D. R. 1992. Critical conditions in determining detergent fibers. Page C-1 in Proc. Natl. Forage Testing Assoc. Forage Anal. Workshop, Denver, CO. Natl. Forage Testing Assoc., Omaha, NE.

NOAA (National Oceanic and Atmospheric Administration). 2006. Climatological data annual summary Wisconsin. Vol. 111. No. 13. National Climatic Data Center, NESDIS, NOAA, Asheville, NC.

NOAA (National Oceanic and Atmospheric Administration). 2007. Climatological data annual summary Wisconsin. Vol. 112. No. 13. National Climatic Data Center, NESDIS, NOAA, Asheville, NC.

NRC. 2001. Nutrient Requirements of Dairy Cattle. 7th rev. ed. National Academy Press, Washington, DC.

Ogden, R. K., W. K. Coblentz, K. P. Coffey, J. E. Turner, D. A. Scarbrough, J. A. Jennings, and M. D. Richardson. 2006. In situ disappearance kinetics of nitrogen and neutral detergent insoluble nitrogen for common crabgrass sampled on seven dates in northern Arkansas. J. Anim. Sci. 84:669-677.

Rotz, C. A., and R. E. Muck. 1994. Changes in forage quality during harvest and storage. Pages 828-868 in Forage Quality, Evaluation, and Utilization. Proc. Natl. Conf. on Forage Quality, Evaluation, and Utilization, Lincoln NE. G. C. Fahey, M. Collins, D. R. Mertens, and L. E. Moser, ed. ASA, CSSA, and SSSA, Madison, WI.

SAS Institute. 1990. SAS/STAT: User's Guide. Version 6. 4th ed. SAS Inst., Cary, NC.

Thomas, J. W., Y. Yu, T. Middleton, and C. Stallings. 1982. Estimations of protein damage. Pages 81-98 in Protein Requirements for Cattle: Symposium. F. N. Owens, ed. Oklahoma State University, Stillwater, OK.

Van Soest, P. J. 1982. Nutritional Ecology of the Ruminant. Cornell Univ. Press, Ithaca, NY.

Van Soest, P. J., J. B. Robertson, and B. A. Lewis. 1991. Methods for dietary fiber, neutral detergent fiber, and nonstarch polysaccharides in relation to animal nutrition. J. Dairy Sci. 74:3583-3597.

Weiss, W. P., H. R. Conrad, and N. R. Pierre. 1992. A theoreticallybased model for predicting total digestible nutrient values of forages and concentrates. Anim. Feed Sci. Technol. 39:95-110.

Weiss, W. P., H. R. Conrad, and W. L. Shockey. 1983. Predicting digestible protein using acid detergent insoluble nitrogen. J. Dairy Sci. 66(Suppl. 1):192. (Abstr.) 